\title{
BILATERAL PAPILLARY RENAL CELL CARCINOMA AND ANGIOMYOLIPOMA IN PATIENTS WITH AUTOSOMAL DOMINANT POLYCYSTIC KIDNEY DISEASE: REPORT OF TWO CASES AND LITERATURE REVIEW
}

\author{
Sachiko Konosu-Fukaya ${ }^{1}$, Yasuhiro Nakamura ${ }^{1}$, Fumiyoshi Fujishima ${ }^{1}$, Atsuko Kasajima ${ }^{1}$, \\ Yayoi Takahashi ${ }^{1}$, Kensuke Joh ${ }^{2}$, Yoshihiro IKeda ${ }^{3}$, NaOmasa Ioritani ${ }^{3}$, Mika Watanabe ${ }^{1}$, \\ HIRONOBU SASANO
}

\begin{abstract}
${ }^{1}$ Department of Pathology, Tohoku University Graduate School of Medicine, Sendai, Japan
2Division of Pathology, Sendai Shakai Hoken Hospital, Sendai, Japan

${ }^{3}$ Division of Urology, Sendai Shakai Hoken Hospital, Sendai, Japan
\end{abstract}

\begin{abstract}
We herein report two rare cases of bilateral renal neoplasms associated with autosomal dominant polycystic kidney disease (ADPKD). Case 1: Bilateral nephrectomy was performed on bilateral renal masses in a 58-year-old man with ADPKD. Case 2: Bilateral nephrectomy was performed on bilateral renal masses in a 32-year-old man with clinically suspected ADPKD. In case 1, angiomyolipoma (AML) and papillary renal cell carcinoma (PRCC) (type 1) were detected in the bilateral kidneys. In case 2, PRCC (type 1) was detected in the bilateral kidneys.
\end{abstract}

Key words: autosomal dominant polycystic kidney disease, papillary renal cell carcinoma, angiomyolipoma.

\section{Introduction}

Autosomal dominant polycystic kidney disease (ADP$\mathrm{KD})$ is a relatively common hereditary renal cystic disease with an incidence of approximately $1: 1,000$, mainly caused by mutations of the PKD1 or PKD 2 gene. To the best of our knowledge, less than 60 cases of renal cell carcinoma (RCC) have been reported in patients with ADPKD [1-6]. Renal angiomyolipoma (AML) accounts for $2.0 \%$ to $6.4 \%$ of all renal neoplasms but no cases have been reported in the bilateral kidneys with ADPKD. In this study, we report two cases of bilateral renal tumors in ADPKD - one with bilateral RCC, the other with RCC and renal $A M L$ - and we review the literature.

\section{Material and methods}

\section{Case 1}

A 58-year-old man with familial history of ADPKD turned out to have bilateral kidney tumors following computed tomography (CT) examination. These bilateral masses were clinically considered as RCC or renal AML in conjuncture with the findings of ultrasonography (US) and magnetic resonance imaging (MRI). One year later, a needle biopsy of the left renal tumor was performed. The mass was histologically diagnosed as RCC and left nephrectomy was subsequently performed. Two years later, right nephrectomy was performed and the patient has been under dialysis since the operation.

\section{Case 2}

A 32-year-old man was clinically suspected to have ADPKD. Both CT and US detected growing renal masses in his bilateral kidneys. Bilateral nephrectomy was subsequently performed followed by hemodialysis. The patient had no clinical findings suggestive of tuberous sclerosis complex (TSC).

\section{Results}

Macroscopically, in both cases, bilateral kidneys were enlarged and numerous cysts of various diameters re- 

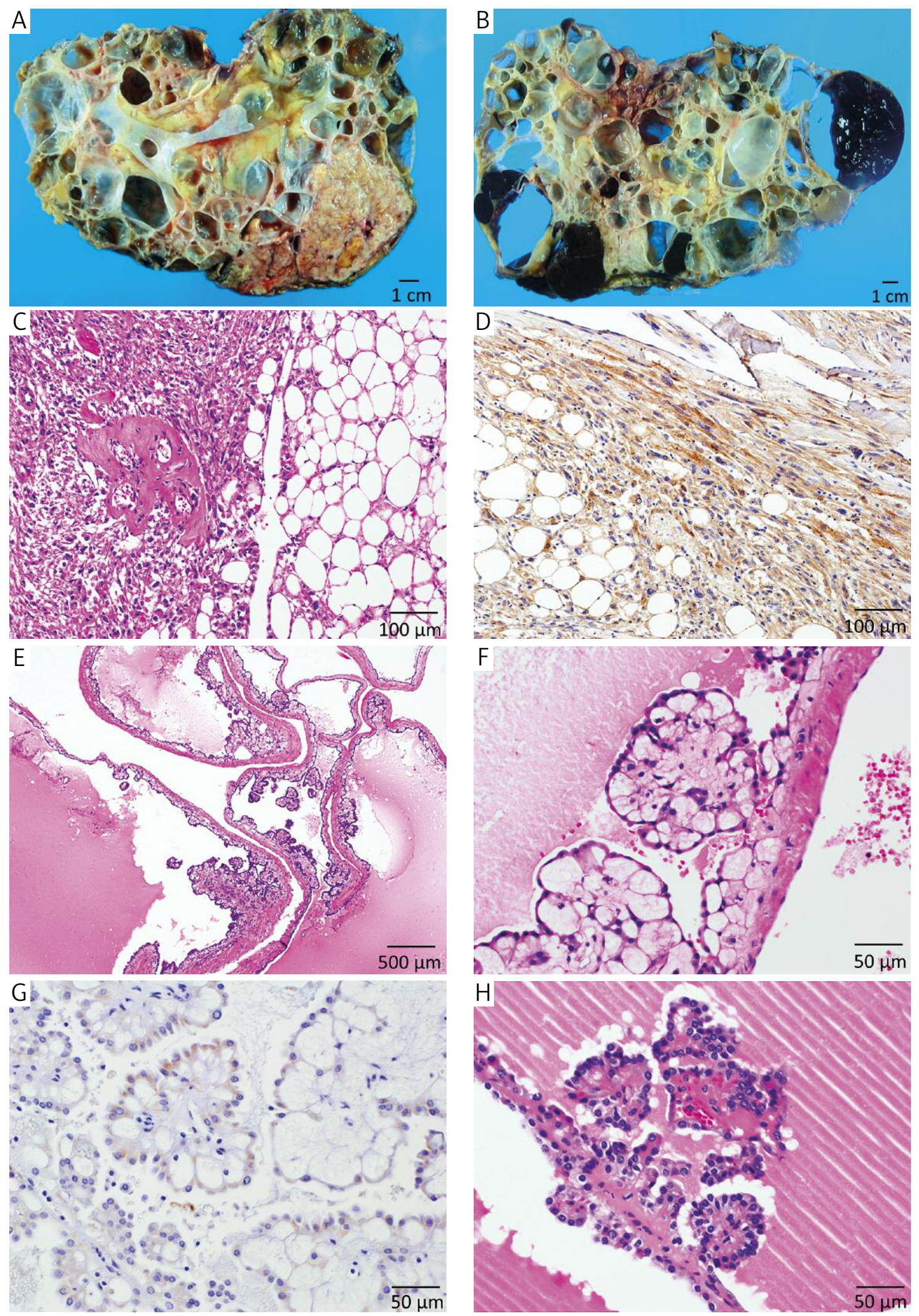

Fig. 1. In case 1, macroscopically, resected kidneys displayed masses with cysts; masses were $7 \mathrm{~cm}$ in the left kidney (A) and $4 \mathrm{~cm}$ in the right kidney (B). Microscopically, the left renal mass was angiomyolipoma (AML) composed of smooth muscle-like cells, vessels and adipocytes (C: magnification 100X). These cells showed positive immunoreactivity to Melan A (D: magnification 100×). Papillary renal cell carcinoma (PRCC) (type 1) was surrounding AML

(E: magnification $40 \times$, F: magnification $200 \times$ ), and it showed positive immunoreactivity for p504s (AMACR)

(H: magnification $200 \times$ ). PRCC was observed in the right kidney as well (H: magnification $200 \times$ ) 
placed the whole renal parenchyma, consistent with ADPKD. In case 1, two masses measuring $7 \mathrm{~cm}$ and $4 \mathrm{~cm}$ in the greatest dimension were detected in the left and right kidneys, respectively (Fig. 1A, B). Microscopically, they were diagnosed as AML, composed of smooth muscle-like spindle cells, hyalinized thickwalled vessels and adipocytes (Fig. 1C). These cells were immunohistochemically positive for melanocytic and myoid markers, i.e. HMB-45, Melan A and $\alpha$-SMA (Fig. 1D). In the vicinity of the AML, papillary RCC (PRCC) (type 1) was detected, characterized by a single layer of cuboidal cells (Fig. 1E, F, H). These cells were immunohistochemically positive for EMA, CD10 and p504s (AMACR) (Fig. 1G), and negative for CK34 $3 E 12$. The Ki67 labeling index of both cases was less than $1 \%$. These findings were all consistent with PRCC (type 1). In case 2, two masses measuring $1 \mathrm{~cm}$ were detected in the bilateral kidneys (Fig. 2A, B). Microscopically, these tumors were also diagnosed as PRCC (type 1) (Fig. 2C-F). These cells were positive for EMA, CD10 and p504s (AMACR) (Fig. 2G, H) and negative for $\mathrm{CK} 34 \beta \mathrm{E} 12$. The Ki67 labeling index of these lesions above was also less than $1 \%$. These findings were also consistent with PRCC (type 1).

Papillary RCC in both cases did not show any lymphatic/vascular invasion, necrosis or extrarenal invasion. TNM stages of both PRCCs were pT1, cN0, cM0, stage I.

\section{Discussion}

The association between ADPKD and RCC has remained in dispute. The state of end-stage kidney disease (ESRD) is considered to increase the overall risk of RCC developing in the patient with ADPKD: approximately half of reported cases are in the state of endstage kidney on hemodialysis [1-8]. However, neither of the two cases in our present study were associated with renal failure. ADPKD-associated RCC occurrs in younger age groups than sporadic RCC; the median age is 45 years old with the range 29 to 67 years old [1]. The mean tumor size is $18 \mathrm{~mm}$ ranging from $8 \mathrm{~mm}$ to $50 \mathrm{~mm}$ [2]. The two cases were consistent with previous reports regarding their age and tumor size. The bilaterality (25\%) and multifocality (29\%) of RCC are also frequently reported in these tumors as in our present cases [3]. Histopathologically, Hajj et al. reported that clear cell RCC was the most common histological subtype in ADPKD (42\%), while the incidence of PRCC was higher in ADPKD than in sporadic RCC [2]. Of 44 patients, they also reported that 9 cases (20\%) were PRCC as in our present cases, significantly higher than that of the general population (12\%) (Table I). Among these cases, five were type 1 and three weretype 2 [3-5]. However, it is also true that ESRD developed into multiple RCC much more often compared to sporadic RCC: $1.6 \%$ to $8.0 \%$ of the patients with ESRD, of whom $23 \%$ to $58 \%$ of the patients had acquired cystic disease of kidney (ACDK) [7]. Most of the RCCs arising in ACDK are associated with specific histological features including acquired cystic diseaseassociated RCC (ACD-RCC) and clear cell papillary RCC [8]. However, the proportion of subtypes of RCC arising in ESRD reported by Tickoo et al. corresponds to that of ADPKD; papillary RCCs were relatively common $(21 \%)$, while clear cell RCCs were common (43\%) [8]. In addition, papillary epithelial hyperplasia and adenoma are frequently detected in ADPKD even in those without renal insufficiency and in ESRD/ACDK $[1,2$, 9]. They are considered as neoplastic lesions with clinical malignant potential [9].

Genetic alterations in ADPKD-associated RCC have remained unknown. Hereditary PRCC syndrome is associated with germ line mutations of the MET oncogene located on 7q31. Sporadic PRCC typically shows

Table I. Summary of cases with papillary renal cell carcinoma (PRCC) arising in autosomal dominant polycystic disease [1-10]

\begin{tabular}{|c|c|c|c|c|c|}
\hline Case & AGE (YEARS)/SEX & No. (PRCC/TOTAL) & $\begin{array}{l}\text { HISTOLOGICAL TYPE OF } \\
\text { PRCC }\end{array}$ & AD (YEARS) & REPORT \\
\hline 1 & NA & NA & unknown & NA & Sulser, 1993 [5] \\
\hline 2 & $\mathrm{NA}$ & $\mathrm{NA}$ & unknown & NA & Gatalica, 1994 [4] \\
\hline 3 & $58 / \mathrm{M}$ & $2 / 4$ & unknown & 16 & Chang, 2007 [3] \\
\hline 4 & 69/M & NA & type 1 & 2 & Hajj, 2009 [2] \\
\hline 5 & $45 / \mathrm{M}$ & $2 / 17$ & $\begin{array}{l}\text { type } 1 \\
\text { type } 2\end{array}$ & 10 & Hajj, 2009 [2] \\
\hline 6 & $48 / \mathrm{M}$ & 1 & type 1 & 1 & Hajj, 2009 [2] \\
\hline 7 & 64/M & $2 / 2$ & $\begin{array}{l}\text { type } 2 \\
\text { type } 2\end{array}$ & 0 & Hajj, 2009 [2] \\
\hline 8 & $58 / \mathrm{M}$ & $2 / 2$ & type 1 & 0 & present case (case 1) \\
\hline 9 & $32 / \mathrm{M}$ & $2 / 2$ & type 1 & 0 & present case (case 2) \\
\hline
\end{tabular}



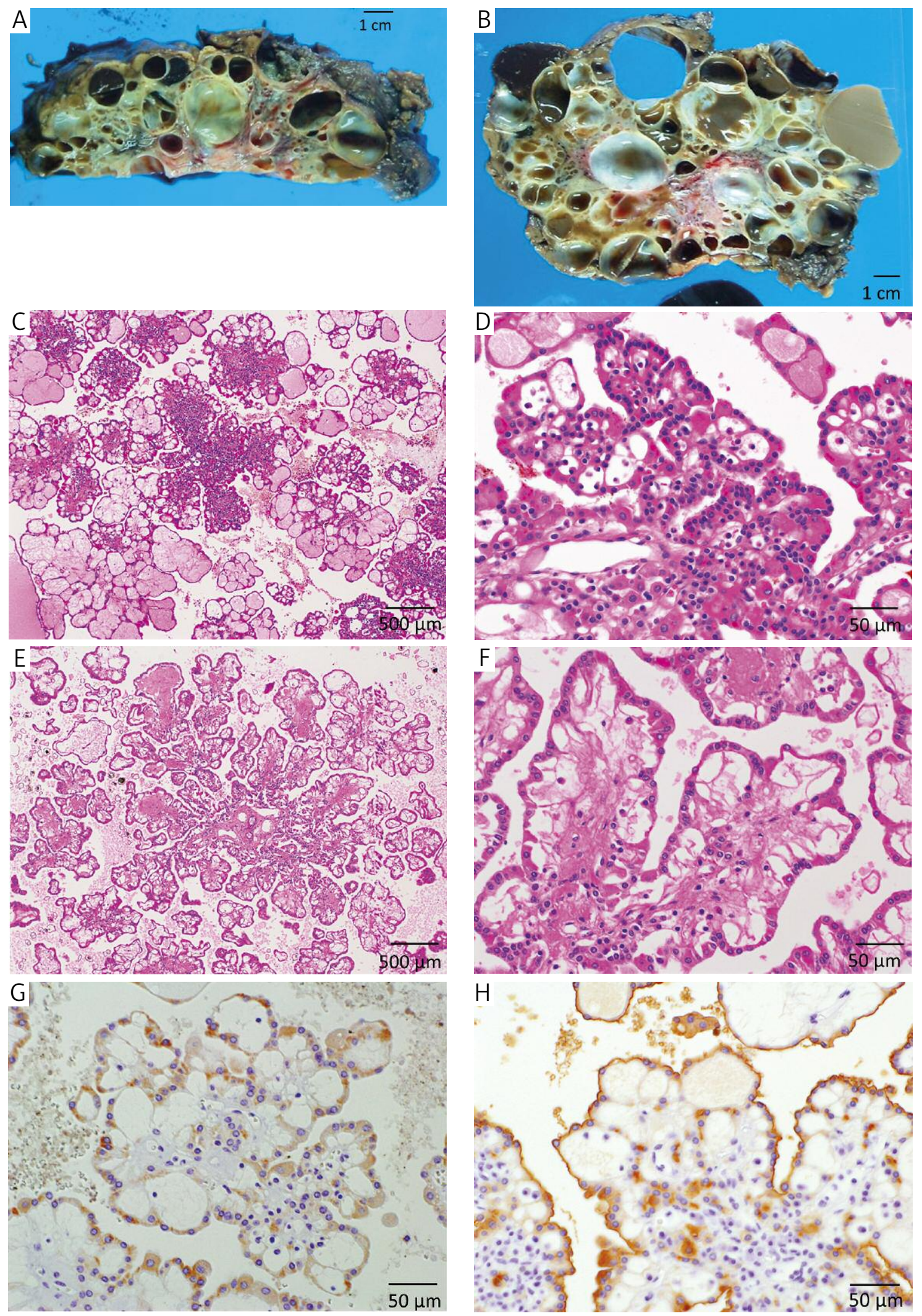

Fig. 2. In case 2, macroscopically, the left kidney (A) and the right kidney (B) displayed masses measuring $1 \mathrm{~cm}$ with cysts. Microscopically, the mass of the left kidney (C: magnification $40 \times$, D: magnification $200 \times$ ) and that of the right kidney (E: magnification $40 \times$, F: magnification $200 \times$ ) were papillary renal cell carcinoma (PRCC) (type 1).

Immunohistochemically, tumor cells of the left kidney were positive for p504s (G: magnification $200 \times$ ) and EMA (H: magnification $200 \times$ ) 
trisomy or tetrasomy of chromosome 7 and 17, and the loss of chromosome $\mathrm{Y}$ in men, which are also detected in PRCC arising in ACDK [10]. Approximately 85\% of ADPKD cases are caused by mutations of the PKD1 gene encoding polycystin 1, which is located within the cell membrane and is involved in cell proliferation and development. Dysfunction of polycystin 1 is considered to result in over-proliferation of tubular epithelial cells and altered cell polarity [11]. PKD1 was also reported to inhibit the mTOR signaling pathway and its activation in ADPKD [12]. However, there have been no reports of the association between PRCC and mTOR. Therefore, the genetic changes processing RCC in ADP$\mathrm{KD}$ requires further investigation.

Renal AML is known as a major manifestation of TSC caused by germ-line mutations of the TSC2 or TSC1 gene, and multiple or bilateral tumors were commonly seen in $80 \%$ of the renal cases [13]. Sporadic AML is also associated with TSC2 gene mutations [14]. PKD1 and TSC2 genes are generally considered to contribute to the pathogenesis of ADPKD and AML, respectively, and are located directly next to each other on chromosome 16p. PKD1/TSC2 contiguous gene syndrome caused by large mutation on both TSC 2 and PKD1 in TSC patients is also reported to result in severe renal dysfunction [15]. Martignoni et al. reported two cases of PKD1/TSC2 contiguous gene syndrome with multiple AML in the bilateral kidneys with diffuse polycystic changes similar to ADPKD [15]. However, there have been only a few reports of renal AML occurring in ADP$\mathrm{KD}$, and the association between ADPKD and AML has remained unknown [2]. To the best of our knowledge, case 1 is the first reported case of bilateral AML without any significant manifestations of TSC, and its clinical presentation is indeed different from that of PKD1/TSC2 contiguous gene syndrome. Therefore, further investigations are required to explore the pathogenesis of AML in ADPKD.

The authors declare no conflict of interest.

\section{References}

1. Keith DS, Torres VE, King BF, et al. Renal cell carcinoma in autosomal dominant polycystic kidney disease. J Am Soc Nephrol 1994; 4: 1661-1669.

2. Hajj P, Ferlicot S, Massoud W, et al. Prevalence of renal cell carcinoma in patients with autosomal dominant polycystic kidney disease and chronic renal failure. Urology 2009; 74: 631-634.

3. Chang YL, Chung HJ, Chen KK. Bilateral renal cell carcino$\mathrm{ma}$ in a patient with autosomal dominant polycystic kidney disease. J Chin Med Assoc 2007; 70: 403-405.

4. Gatalica Z, Schwarting R, Petersen RO. Renal cell carcinoma in the presence of adult polycystic kidney disease. Urology 1994; 43: 102-105.

5. Sulser T, Fehr JL, Hailemariam S, et al. Papillary renal cell carcinoma associated with autosomal dominant polycystic kidney disease. Urol Int 1993; 51: 164-166.
6. Nishimura H, Ubara Y, Nakamura M, et al. Renal cell carcinoma in autosomal dominant polycystic kidney disease. Am J Kidney Dis 2009; 54: 165-168.

7. Bonsib SM. Renal cystic diseases and renal neoplasms: a minireview. Clin J Am Soc Nephrol 1998; 4: 1998-2007.

8. Tickoo SK, dePeralta-Venturina MN, Harik LR, et al. Spectrum of epithelial neoplasms in end-stage renal disease: an experience from 66 tumor-bearing kidneys with emphasis on histologic patterns distinct from those in sporadic adult renal neoplasia. Am J Surg Pathol 2006; 30: 141-153.

9. Bernstein J, Evan AP, Gardner KD Jr. Epithelial hyperplasia in human polycystic kidney diseases. Its role in pathogenesis and risk of neoplasia. Am J Pathol 1987; 129: 92-101.

10. Gronwald J, Baur AS, Holtgreve-Grez H, et al. Chromosomal abnormalities in renal cell neoplasms associated with acquired renal cystic disease. A series studied by comparative genomic hybridization and fluorescence in situ hybridization. J Pathol 1999; 187: 308-312.

11. Huan Y, van Adelsberg J. Polycystin-1, the PKD1 gene product, is in a complex containing E-cadherin and the catenins. J Clin Invest 1999; 104: 1459-1468.

12. Ibraghimov-Beskrovnaya $\mathrm{O}$, Natoli TA. mTOR signaling in polycystic kidney disease. Trends Mol Med 2011; 17: 625-633.

13. Steiner MS, Goldman SM, Fishman EK, et al. The natural history of renal angiomyolipoma. J Urol 1993; 150: 1782-1786.

14. Henske EP, Neumann HP, Scheithauer BW, et al. Loss of heterozygosity in the tuberous sclerosis (TSC2) region of chromosome band 16p13 occurs in sporadic as well as TSC-associated renal angiomyolipomas. Genes Chromosomes Cancer 1995; 13 : 295-298.

15. Martignoni G, Bonetti F, Pea M, et al. Renal disease in adults with TSC2/PKD1 contiguous gene syndrome. Am J Surg Pathol 2002; 26: 198-205.

\section{Address for correspondence}

Yasuhiro Nakamura MD, $\mathrm{PhD}$

Department of Pathology

Tohoku University School of Medicine

2-1 Seiryo-machi, Aoba-ku, Sendai

980-8575 Japan

tel. $+81-22-717-8050$

fax +81-22-717-8051

e-mail: yasu-naka@patholo2.med.tohoku.ac.jp 